\title{
Los derechos de asociación y reunión: nuevas perspectivas dogmáticas y jurisprudenciales ${ }^{* *}$
}

\author{
The rights of association and assembly: new perspectives \\ dogmatic and jurisprudential
}

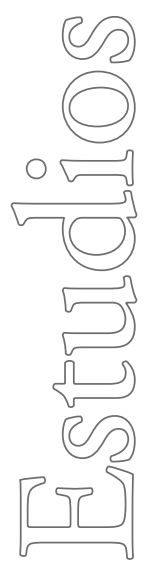

\section{Resumen:}

Este artículo contiene el estudio de los conceptos de los derechos de asociación y reunión, su contenido y desarrollo constitucional y legal, y reglamentario tratándose del derecho de reunión en lugares públicos, dando una mirada a los límites que se le imponen. Particularmente, considera la doctrina jurisprudencial y los alcances de la reforma constitucional de 2005 sobre dos aspectos muy debatidos del derecho de asociación: colegiación obligatoria y tuición ética de las profesiones.

Palabras claves:

Derecho de asociación, derecho de reunión, colegiación profesional.

* Profesor Titular de Derecho Constitucional, Facultad de Derecho, Universidad de Chile.

** Artículo recibido el 10 de octubre de 2013 y aceptado para su publicación el 12 de noviembre de 2013.

\begin{abstract}
:
This article contains the study of the concepts of the rights of association and assembly, content and legal and constitutional development, and regulatory case the right of assembly in public places, giving a look to the limits that are imposed. Particularly, considers the jurisprudence and scope of the constitutional reform of 2005 on two very debated aspects of the right of association: tuition compulsory and ethics of professions.
\end{abstract}

Key words:

The right of association, freedom of assembly, professional association. 


\section{Presentación}

La invitación a escribir sobre los derechos de asociación y de reunión, en sus nuevas perspectivas dogmáticas y jurisprudenciales, no puede estar divorciada de un contexto de normalidad institucional, en que estos derechos duales se desenvuelven, ya que parte significativa de la reflexión contemporánea y clásica de estos, dicen relación con un contexto fáctico de fuerza, sean regímenes autocráticos o estados de excepción ${ }^{1}$.

Hemos de definir y situar tipológicamente los derechos de asociación y de reunión como derechos duales, ya que empleando la consolidada tipología histórico-positiva de derechos: derechos civiles, derechos políticos y derechos económicos, sociales y culturales, estos derechos pueden ser estudiados como derechos civiles o bien como derechos políticos, precisamente en razón de la dimensión individual y colectiva que su titularidad, ejercicio y fines poseen, por una parte, y la conexión directa que tienen con la política y las fuerzas políticas organizadas y no organizadas. Asimismo, como bien anota el jurista Manuel A. Núnéz, estos derechos fundamentales tienen en común el concernir a "agrupaciones de personas que reconocen entre sí algún tipo de relación recíproca", relación que se basa en una "finalidad común que no es posible conseguir sino en alianza voluntaria con los demás"; de cual deriva la circunstancia de tratarse de derechos eminentemente instrumentales o "funcionales".

Lo anterior sitúa a los derechos de asociación, en especial el derecho de asociación política y al derecho de reunión en estrecha ligazón con el sistema democrático pluralista. La única particularidad es que en nuestro ordenamiento constitucional el derecho de asociación política, circunscrito a la formación de partidos políticos, es un derecho político autónomo del derecho de asociación matriz.

Por último debemos destacar que en nuestro abordaje propedéutico de los derechos de asociación y de reunión, pondremos especial acento en su definición, contenido, desarrollo infraconstitucional, legal tratándose del derecho de asociación y reglamentario tratándose del derecho de reunión en lugares públicos, los límites que se imponen por tal desarrollo, sumariamente un recorrido a la doctrina jurisprudencial y más detenidamente los alcances de la reforma constitucional de 2005 sobre dos aspectos muy debatidos del derecho de asociación: colegiación obligatoria y tuición ética de las profesiones.

\footnotetext{
Un desarrollo dogmático de los derechos en nuestro medio se encuentra en el libro de Aldunate Lizana (2008). Un interesante desarrollo propedéutico acerca de derechos fundamentales en el libro de Cea Egańa (2004). También es muy valioso el trabajo de Núńez (1997). Finalmente debemos citar el trabajo de Silva Bascuñán (2009), pp. 305-317.
} 


\section{Derecho de Asociación}

Como lo hemos sostenido en otro lugar el derecho de asociación es un derecho dual y complejo, tiene una dimensión positiva y otra negativa, es un derecho civil, que abre la puerta a un derecho político autónomo el derecho de asociación política, e importa en su dimensión institucional una conexión con el pluralismo social de cuerpos intermedios de la sociedad civil y su autonomía, el reconocimiento de una suerte de derecho de fundación para que las personas puedan constituir asociaciones en conformidad a la ley y dotadas de personificación, dentro del marco de licitud que la reserva legal determine. En nuestro medio Nogueira Alcalá propone precisar en qué consiste el derecho de asociación y cuál es su contenido: "Este derecho constituye la facultad que tienen todas las personas para ejercer la libertad de crear asociaciones y de adscribirse a las que ya estén creadas, la libertad para no asociarse y para dejar de pertenecer a asociaciones, la libertad de determinar sus fines, la organización de ellas y la determinación de su funcionamiento interno sin interferencias públicas y el conjunto de facultades que tienen los asociados individualmente considerados frente a las asociaciones de que forman parte o frente a aquellas en que buscan integrarse". Agrega Nogueira Alcalá: "Las asociaciones constituyen la unión de dos o más personas, en forma libre y voluntaria, con una o más finalidades común de carácter particular o de interés general de carácter lícito o no prohibido por el ordenamiento jurídico, bajo un régimen organizado de formación de su voluntad, comprometiéndose a poner en común actividades, recursos económicos, conocimientos, con carácter temporal o indefinido". Finalmente, nos recuerda este autor acerca de la doctrina jurisprudencial relativa al derecho de asociación que el Tribunal Constitucional ha ensayado una definición del derecho de asociación, determinado que es "(...) la facultad de una persona de unirse a otras, en forma voluntaria y con cierto grado de permanencia para la realización común de un fin determinado (...)".A su vez, la Corte Interamericana de Derechos Humanos ha precisado que el derecho a la libertad de asociación “(...) Se trata, pues, del derecho fundamental de agruparse para la realización común de un fin lícito sin presiones o intromisiones que puedan alterar o desnaturalizar su finalidad"2.

Como lo hemos planteado en otro lugar el derecho de asociación tiene dos dimensiones: una positiva y otra negativa. En su dimensión positiva, es un derecho fundamental de autonomía, es la libertad para crear, dotar de fines y organizar asociaciones, como para integrarse a ellas. En esta dimensión el derecho de asociación es la "facultad de toda persona para acordar agruparse con otras e instituir una organización relativamente estable que les facilite conseguir un fin determinado" (M. A. Núñez) En su dimensión negativa, es un derecho fundamental de libertad negativa, es la libertad de las personas para afiliarse o no a asociaciones, también denominada libertad de asociación o libertad de afiliación, y en tal sentido, se reconoce la autonomía de la voluntad de las personas para tomar la decisión de ingresar o no a una asociación,

2 Nogueira Alcalá (2008), pp. 548-549. 
como lo establece con claridad el inciso tercero del No 15 y el inciso cuarto del No 16 del artículo 19 de la Constitución, plenamente concordante con la libertad de afiliación sindical del No 19 del artículo 19 de la misma Carta. De manera tal que amenazar a personas con la eliminación de una actividad laboral, empresarial, comercial, gremial, social o de cualquier otro tipo por el hecho de no afiliarse a un tipo determinado de asociación, constituye una coacción claramente violatoria de la dimensión negativa garantizada de la libertad de asociación o de sindicación en su caso. En ello la huella ideológica del constituyente autoritario y neoliberal de 1980, vuelven a ser nítida y permite rastrear una Constitución Económica y Social hostil a la intervención del Estado en la economía y sociedad, y hostil al trabajo, a los trabajadores y a los derechos sociales.

Recuerda NOGUEIRA ALCALÁ la dimensión objetiva o institucional del derecho de asociación al señalar: "Esta autonomía o derecho de autoorganización corresponde a la asociación como ente colectivo, que le permite dotarse de sus reglas de funcionamiento, determinar sus órganos internos y sus respectivas competencias, los derechos y deberes de los asociados, el desarrollo de sus actividades sin interferencias de los poderes públicos. La organización interna de las asociaciones tiene una gran importancia, ya que determinan los derechos y obligaciones de los asociados, el objeto social, los órganos y sus competencias, el patrimonio y su aplicación, por lo cual los estatutos sociales deben ser objeto de especial consideración. La autonomía organizativa o libre autoorganización toma forma en los estatutos de la asociación, que constituyen la Constitución interna de la asociación, ya que determina su nombre y símbolos, sus órganos y competencias, los derechos y deberes de los asociados, los objetivos perseguidos, regulan el patrimonio y su gestión, precisan los requisitos de admisión y expulsión de socios. El legislador puede establecer, al regular el derecho de asociación, condiciones y requisitos de ejercicio del derecho, como asimismo limitaciones a la autonomía de la voluntad de los asociados en cuanto a determinados aspectos de la organización y funcionamiento de la asociación, la existencia de determinados órganos internos mínimos, el respeto de los principios básicos democráticos en el funcionamiento institucional, la duración máxima de los cargos, las atribuciones básicas de la asamblea de asociados, las atribuciones básicas del órgano de gobierno de la asociación, entre otros. Estas restricciones o injerencias en el derecho a la libertad de asociación, de acuerdo con las disposiciones antes señaladas de la Convención Americana sobre Derechos Humanos y del Pacto Internacional de Derechos Civiles y Políticos de Naciones Unidas, sólo pueden estar previstas por la ley, ello implica que únicamente el legislador formalmente previsto en el sistema constitucional estatal, con el procedimiento previsto en la misma Carta Fundamental para aprobar las leyes, puede establecer restricciones o limitaciones al ejercicio del derecho de asociación, hay así una reserva de la ley expresa en la materia, cuya vulneración implica ya una violación tanto de la Convención Americana como del Pacto Internacional de Derechos Civiles y Políticos, antes señalados, en sus artículos 16 y 22, respectivamente, como asimismo del artículo 19 № 15 de la Constitución"3.

Nogueira Alcalá (2008), pp. 551-552. 
En la doctrina jurisprudencial de la Corte Interamericana de Derechos Humanos sobre la reserva de ley y los límites legítimos al derecho de asociación se sostiene: "Asimismo, la Convención no se limita a exigir la existencia de una ley para que sean jurídicamente lícitas las restricciones al goce y ejercicio de los derechos y libertades, sino que requiere que las leyes se dicten por razones de interés general y con el propósito para el cual han sido establecidas".

Por último, el desarrollo infraconstitucional del derecho de asociación exige que la ley formal-material sea fruto de un procedimiento constitucionalmente consagrado y teniendo fines legítimos, debe ser "necesaria en una sociedad democrática" vale decir, en una sociedad tolerante, abierta, pluralista.

Antes de concluir la explicación de nivel conceptual acerca del derecho de asociación (significado, contenido, desarrollo legislativo y límites), es menester destacar que es este derecho dual una pieza basal del pluralismo social y político, y la riqueza de fines a perseguir lo demuestran. Bien destaca NOGUEIRA ALCALÁ: "Los fines constituyen los intereses comunes de los asociados, siendo el objeto de la asociación un elemento instrumental al desarrollo de tales fines. Es evidente que los fines perseguidos por las asociaciones deben ser fines lícitos y conformes al ordenamiento jurídico, vale decir conforme a la Constitución y las leyes. De acuerdo a sus fines pueden clasificarse las asociaciones en aquellas que persiguen fines de lucro (por ejemplo, sociedades comerciales) de aquellas que no los tienen (fundaciones y corporaciones); en asociaciones con un interés público o con intereses particulares; en asociaciones con un fin único o con fines múltiples. Los fines también influyen en la organización de la asociación y en el tratamiento o regulación específica que le otorga en ordenamiento jurídico. En efecto el ordenamiento jurídico le da un tratamiento diferenciado a las asociaciones laborales o sindicatos, a las asociaciones gremiales o colegios profesionales, entre otras asociaciones" ${ }^{\text {". }}$.

Enseguida, lo que corresponde abordar en este trabajo propedéutico es el alcance de la reforma constitucional de 2005 en relación al derecho de asociación y sus consecuencias contextuales para el viejo debate acerca de la colegiación obligatoria y la tuición ética de las profesiones. La reforma constitucional de 2005 restablece el control ético de las profesiones en el No 16 del artículo 19 de la C.P.R. Tuvo su origen en el Senado y apoyada mayoritariamente en la Cámara de Diputados pero sin alcanzar el quórum necesario de los dos tercios para ser norma constitucional, por lo que fue materia de veto aditivo. Tal reforma se sitúa en el contexto de la libertad de trabajo, libertad contractual y libertad profesional, pero tiene una estrecha ligazón con el derecho de asociación ${ }^{5}$.

En efecto desde una perspectiva dogmática el control o tuición ética de los colegios profesionales conecta con los derechos de asociación y libertad de asociación. El derecho de asociación en nuestro orden constitucional tiene un amplio ámbito, ya que com-

Nogueira Alcalá (2008), p. 554.

Bulnes Aldunate (1981), pp. 121-138. 
prende todas las formas asociativas del pluralismo social, es decir, desde organizaciones comunitarias, hasta personas jurídicas y sociedades civiles y mercantiles de derecho privado, pasando por asociaciones gremiales, aunque ciertamente las personas jurídicas con fines de lucro conectan con la libertad de empresa y el derecho de fundación comprendidos en la libertad económica del No 21 del artículo 19 de la C.P.R. También existe una conexión con el derecho de sindicación y el derecho de asociación política. Por lo demás así lo ha entendido el Tribunal Constitucional al señalar "Que el derecho de asociación concebido en su más pura y natural expresión, como la facultad de una persona para unirse con otras, en forma voluntaria y con cierto grado de permanencia para la realización común de un fin determinado, se encuentra ampliamente asegurado por el Constituyente quien ni lo somete a prescripción legal alguna para su ejercicio ni dispone que requiera de permiso previo, imponiéndole sólo la limitación de no ser contrario a la moral, al orden público o a la seguridad del Estado" (STC Rol No 43, cons. 12). La amplitud del derecho de asociación es resultado de la importancia que posee el pluralismo social.

Desde la perspectiva del pluralismo social las asociaciones (cuerpos o grupos intermedios voluntarios) constituyen canales de influencia entre los individuos y el Estado. "La democracia -recuerda Stein- es tanto más real cuanto mayor libertad existe para las corrientes de opinión y de voluntad de los individuos desemboquen, por medio de pequeńas y grandes asociaciones, en la formación de la voluntad estatal a través del Parlamento. Se trata, por tanto, en primer término de un problema de integración" ${ }^{6}$.

El derecho de asociación, nos recuerda Stein, es dual: por una parte es una libertad positiva (derecho de asociación) y por otra parte es una libertad negativa (libertad de asociación), de recepción tardía en el constitucionalismo liberal, que con la revolución burguesa del siglo XVIII abolió las corporaciones y gremios, de naturaleza jerárquicos y monopólicos, y todas las medidas opuestas al libre tráfico de la fuerza de trabajo y circulación de la riqueza, de lo cual son un botón de muestra en Francia son la Ley de 1791 sobre libertad de oficios y profesiones, la Ley Le Chapelier que prohibía las asociaciones gremiales; de las cuales se hace eco el Código de Napoleón de 1810 que castiga como delito a las asociaciones. "La inquina -dice agudamente Pérez Royo-al ejercicio del derecho de asociación lo era contra el ejercicio de dicho derecho en su vertiente política y, sobre todo, sindical. La constitución de asociaciones que pudieren insertarse como intermediarios entre el ciudadano y el Estado, en el primer caso, y que pudieren incidir en la relación contractual entre el empresario y el trabajador, en el segundo, es lo que convertía a estas asociaciones en intelectual y prácticamente repugnantes para la mentalidad individualista dominante en el momento de la inicial puesta en marcha del Estado Constitucional"'. En el constitucionalismo liberal burgués

Stein (1973), p. 150.

Pérez Royo (1999), p. 450. 
las sociedades civiles y comerciales no son fruto del derecho de asociación sino de la tradicional "libertad de industria y comercio".

De este modo, ante la desconfianza del constitucionalismo liberal por el asociacionismo, sólo tardíamente se reconoce en los catálogos de derechos estas libertades, ligadas incluso al mutualismo o al sindicalismo más tarde. También muy tardíamente el constitucionalismo liberal admite el reconocimiento de los partidos políticos y muy a regańadientes el "Estado de Partidos"o democracia de partidos. En particular en Chile el derecho de asociación se incorpora al catálogo de derechos de la Constitución pelucona de 1833 con la reforma de 1874 (artículo 12 № 6) y los derechos de asociación política y sindicación se incorporan con la reforma de 1971 o Estatuto de Garantías a la Constitución de 1925. (art. 9 nuevo y No 14 del artículo 10 nuevo incorporado por Ley No 17.398).

Además debemos destacar que la naturaleza del derecho de asociación y su ligazón con el derecho de asociación gremial ha dado origen a un interesante debate en la doctrina germana. Para KASKEL el derecho de asociación gremial (profesional) es una especie del derecho de asociación general, que da cobertura a constituir personas jurídicas o colectivas con diverso estatuto legal y fines. En cambio NIPPERDEY sostiene que la libertad de asociación gremial es un derecho fundamental especial, que confiere la facultad de constituir asociaciones de diversos fines compatibles con el derecho. Además el derecho de asociación plantea problemas gruesos acerca de la personificación y los atributos de la personalidad, que también son abordados desde perspectivas privatistas ${ }^{8}$.

Lo cierto es que la configuración constitucional de nuestro derecho de asociación (separado del derecho de asociación política y del derecho de sindicación del art. 19 No 19 C.P.R.) basado en un explícito principio de pluralismo social, nos permite diferenciar claramente la libertad positiva de la libertad negativa, la primera reforzada por la garantía de personalidad jurídica en conformidad a la ley y la segunda reforzada por el mandato de prohibición del inciso $4^{\circ}$ del No 16 del art. 19 C.P.R.

De esta suerte la libertad positiva se ejerce, sin permiso previo, junto a otras personas naturales o jurídicas, dándose reglas y fines comunes, obteniendo personalidad jurídica en conformidad a la ley, la que arbitra diversos estatutos, fundados en un pacto genético o concurso de voluntades (lo que da pie para distinguir entre asociaciones de hecho y de iure); y la libertad negativa redunda en la garantía de no obligatoriedad de pertenecer a asociación alguna. En el fondo la libertad positiva comprende un "derecho de autoorganización” (Pérez Royo) que le da cobertura a sus acuerdos, reglamentaciones interna

8 En términos generales es útil el libro de Garrigou Lagrance (1974), y de Lucas Murillo de la Cueva (1996). Garrigou nos recuerda que el asociacionismo en Francia tiene su punto de partida con la Ley de $1^{\circ}$ de julio de 1901 sobre contrato de asociación, definido este como "el pacto por el cual dos o más personas ponen en común de manera permanente sus conocimientos y su actividad con un fin distinto al reparto de beneficios", diferenciando a estas asociaciones-corporaciones de las sociedades. En particular sobre colegiación y sanciones es útil el libro de López González (2001), pp. 127-143, 157-166. 
corporis acta y estatutos en general. A tales dimensiones, se suma la garantía de una norma o mandato de prohibición enderezado a las asociaciones contrarias a la "moral, al orden público y a la seguridad del Estado”, con una necesaria y amplísima, por el uso de conceptos jurídicos indeterminados, remisión al legislador (civil, mercantil y penal) de desarrollo de este mandato?.

Esta configuración constitucional del binomio de libertades positiva y negativa, importan dar cobertura a un derecho interna corporis (derecho infra estatal y sub lege, propiamente ordinamentalista, usando el concepto de Santi Romano) de las asociaciones constituidas en conformidad a la ley, que comprende los diversos aspectos de la vida social o gremial, incluida su "jurisdicción doméstica". ${ }^{10} \mathrm{~A}$ nuestro juicio la reforma constitucional dota a los colegios profesionales de una "jurisdicción" más que "doméstica" frente sus miembros, al devenir los colegios en personas jurídicas que ejercen una función pública ope Constitutione.

Es menester tener presente que la Constitución establece la libertad de asociación (No 15 del art. 19 C.P.R.) en congruencia con el principio de pluralismo social del art. $1^{\circ}$ que reconoce y ampara los cuerpos intermedios de la sociedad civil y su autonomía. La libertad de asociación tiene su antecedente en el No 9 del art. $1^{\circ}$ del Acta Constitucional No 3 (D.L. No 1552 de 1976), a la que se agregaba en el No 20 , inciso $6^{\circ}$ que la "colegiación será obligatoria en los casos exigidos por la ley, la cual sólo podrá imponerla para el ejercicio de una profesión universitaria”; texto finalmente suprimido de la Carta por el constituyente autoritario de 1980. Incluso más un precepto similar a éste del Acta Constitucional No 3 estaba contenido en los anteproyectos de la Comisión de Estudio de la Nueva Constitución Política de la República de Chile (CENC) y del Consejo de Estado, y fundando la Comisión la colegiación de profesiones universitarias argumenta: "Sólo por excepción, y al tratar de la libertad de trabajo, hemos estimado conveniente establecer que para el ejercicio de aquellas profesiones universitarias que seńale la ley es obligatoria la colegiación, excepción que se justifica plenamente por la naturaleza, importancia y responsabilidad que implica el ejercicio de una profesión y por las facultades jurisdiccionales que en materia de ética profesional se entrega a los respectivos colegios" (“Anteproyecto Constitucional y sus Fundamentos", p. 99).

A pesar de la libertad negativa plena y de la libertad de las profesiones consagrada en nuestra Constitución, en nuestro medio se ha planteado por el jurista Lautaro Ríos la inconstitucionalidad del D.L. No 3621, de 1981, que convierte los tradicionales colegios profesionales en asociaciones gremiales regidas por el D.L.

9 En nuestro medio Lautaro Ríos introduce, usando categorías discutibles en el Derecho Constitucional del país, el derecho de asociación en la doctrina de las garantías institucionales y de instituto de Martin Wolf y Carl Schmitt, distinguiendo entre libertad asociativa aplicable a las "sociedades voluntarias" y garantía institucional, que cautela la esencia del derecho fundamental aplicable a las "asociaciones necesarias". Ríos Álvarez (1999b), Tomo I., pp. 141-158. De Schmitt (1982), pp. 175-179; que pone en evidencia en el contexto de Weimar la funcionalidad ideológica de categorías como las garantías institucionales y de instituto, para oponerse al, en principio, temido legislador democrático.

10 Muñoz B. (1999), Tomo II, pp. 327-347. 
No 2757, de 1979, en consonancia con la prohibición de colegiación obligatoria, privando a los colegios de la tuición ética y de la potestad de dictar aranceles, fundando la inconstitucionalidad de estos cuerpos legales en su contradictoriedad temporal con No 20 del art. $1^{\circ}$ del Acta Constitucional No 3 y con el inciso $3^{\circ}$ del art. $1^{\circ}$ C.P.R. ${ }^{11}$.

La reforma sobre tuición ética de los colegios profesionales concierne a la libertad de trabajo en general y a la libertad de elección de profesiones y oficios del No 16 del art. 19 C.P.R. En este contexto debemos distinguir entre la elección de profesiones y oficios y el ejercicio de éstas, y la necesaria conexión de esta libertad con el derecho a la educación, libertad de enseńanza y con la libertad económica de los No 10,11 y 21 del artículo 19. De esta suerte la libertad de elección profesional sólo puede limitarse por la "fuerza impediente de la realidad" o si se prefiere, por razones de estricta organización, como ocurre con los numerus clausus, ya que esta libertad forma parte del "desenvolvimiento humano, del desarrollo vocacional de la personalidad, y por lo tanto, no puede ser sometida a trabas" (Tolivar); pero el ejercicio profesional puede ser sometido a un amplio abanico de limitaciones, pues se salvaguarda la competencia o solvencia profesional, para impedir "daños masivos a terceros". Además se cautela la "imagen profesional" en virtud de la cual cada actividad profesional se identifica socialmente con una imagen típica asumida por la población, que incluye las funciones tradicionales de una profesión, condiciones de idoneidad, presupuestos económicos y límites convencionales de dicha actividad ${ }^{12}$.

También la distinción entre libertad profesional y ejercicio de ésta, tiene especial importancia tratándose de profesiones tituladas en las que el Estado tiene cometidos irrenunciables, el más básico es la colación de grados; ya que le corresponde "inexcusablemente fijar qué profesiones exigen título facultativo y no pueden ejercerse sin una garantía oficial de suficiencia, y asimismo le compete, con exclusiva indisputable, establecer las condiciones en que podrá obtenerse el certificado que acredite haber demostrado la destreza apetecible para la función de que se trate" (Pérez Serrano). Consiguientemente la Ley No 18.962 orgánica constitucional de Enseñanza junto con establecer el reconocimiento oficial de la educación superior (Título III) dispone que los establecimientos de este nivel (centros de formación técnica, institutos profesionales, universidades y academias) otorgarán títulos técnicos de nivel superior, títulos profesionales y grados académicos, fijando los mínimos (arts. 29 y 31), e identificando las profesiones tituladas que requieren de grado de licenciado (art.52).

En la reforma comentada el control ético de las profesiones por colegios constituidos en conformidad a la ley (asociaciones gremiales) distingue dos situaciones: la de los profesionales colegiados y la de profesionales que no pertenecen a un colegio. En la primera situación, se le otorga al propio colegio profesional respectivo, en

\footnotetext{
Ríos Álvarez (1996a), pp. 185-205

12 Tolivar Alas (1991), tomo II, pp. 1337-1370. También Villar Palasí y Villar Ezcurra (1991), pp. 1371-1413.
} 
primera instancia, la facultad de conocer de las reclamaciones que se interpongan por conductas contrarias a la ética profesional de sus asociados. Estas decisiones de control ético pueden ser apeladas ante las Cortes de Apelaciones respectivas. En la segunda situación, los profesionales no asociados serán juzgados por los tribunales especiales que se deben crear por ley a este efecto. La disposición transitoria (20a) sustituye temporalmente a los tribunales especiales que deben crearse, por los tribunales ordinarios y mientras no exista esa ley. Desde una perspectiva de lege ferenda es toral respetar el principio de igualdad constitucional, sus derechos y garantías, en particular asegurando que el derecho material (ética de las profesiones) sea común o posea estándares comunes, y la presencia en los tribunales especiales que establezca la ley de jueces escabinos con conocimientos en la lex artis y en la ética de las profesiones particulares; evitando así un incentivo perverso a la desafiliación a los colegios profesionales.

Finalmente anotamos que la reforma establece un mandato implícito de habilitación al legislador para someter a los colegios profesionales a un estatuto distinto al de las asociaciones gremiales. Este mandato de habilitación está en consonancia con la libertad de asociación y con el deber del Estado de reconocer y amparar a los cuerpos intermedios de la sociedad civil así como asegurar su autonomía (art. $1^{\circ}$ C. P.R.), de suerte que se pueden imponer limitaciones, más allá del campo de las "asociaciones prohibidas" (inciso $4^{\circ}$ del No 15 del art. 19 C.P.R.), que sean necesarias en una sociedad democrática, en interés de la seguridad nacional, de la seguridad pública o del orden público, o para proteger la salud o la moral públicas o los derechos de los demás (art. 22 del Pacto Internacional de Derechos Civiles y Políticos y art. 16 del Pacto de San José de Costa Rica). ${ }^{13}$

Este estatuto distinto para los colegios profesionales es consecuencia directa además de un alcance de la reforma constitucional al dotar a estos colegios de una finalidad pública o estatal: velar por la ética, decoro y competencia profesional de los integrantes de una orden. Ello arranca de la distinción misma entre personas jurídicas de derecho privado y de derecho público, que para privatistas clásicos como FERRARA y COVIELLO, señalan para las personas jurídicas públicas el carácter de instituciones creadas para satisfacer un "interés especial, dotadas de capacidad pública” para velar por las profesiones, disciplina, decoro, entre otros fines, participando así en la "vida pública” y colaborando con una función del Estado. ${ }^{14}$ En consecuencia, a nuestro juicio, los colegios profesionales en virtud de la reforma devienen en personas jurídicas cooperadoras del Estado en una función pública: la guarda de la ética profesional y la competencia de las profesiones de sus afiliados o miembros.

Por último resulta de interés traer a este comentario la Opinión Consultiva sobre Colegiación Obligatoria de Periodistas de la Corte Interamericana de Derechos Humanos, que interpreta los art. 13 y 29 de la Convención Americana sobre Derechos

\footnotetext{
Consultar a Silva Bascuñan (1980).

Ferrara (1929), pp. 360- 414, 698-701. También Coviello (1938), pp. 221-222.
} 
Humanos, y la compatibilidad con dicho tratado de la Ley No 4.420 de la república de Costa Rica que establece colegiación obligatoria para ejercer el periodismo. En lo pertinente y extractadamente la Opinión Consultiva señala:

"68. La Corte observa que la organización de las profesiones en general, en colegios profesionales, no es per se contraria a la Convención, sino que constituye un medio de regulación y de control de la fe pública $y$ de la ética a través de la actuación de los colegas. Por ello, si se considera la noción de orden público en el sentido referido anteriormente, es decir, como las condiciones que aseguran el funcionamiento armónico y normal de las instituciones sobre la base de un sistema coherente de valores y principios, es posible concluir que la organización del ejercicio de las profesiones está implicada en ese orden".

"69. Considera la Corte, sin embargo, que el mismo concepto de orden público reclama que, dentro de una sociedad democrática, se garanticen las mayores posibilidades de circulación de noticias, ideas y opiniones, asi como el más amplio acceso a la información por parte de la sociedad en su conjunto. La libertad de expresión se inserta en el orden público primario y radical de la democracia, que no es concebible sin el debate libre y sin que la disidencia tenga pleno derecho de manifestarse.

En ese sentido, la Corte adhiere a las ideas expuestas por la Comisión Europea de Derechos Humanos cuando, basándose en el Preámbulo de la Convención Europea, señaló: Que el propósito de las altas Partes Contratantes al aprobar la Convención no fue concederse derechos y obligaciones reciprocas, con el fin de satisfacer sus intereses nacionales sino (...) establecer un orden público común de las democracias libres de Europa, con el objetivo de salvaguardar su herencia común de tradiciones politicas, ideales, libertad y régimen de derecho. ('Austria vs. Italy', Application $N^{\circ} 788 / 60$, European Yearbook of Human Rights (1961), Vol 4, p. 138.)

También interesa al orden público democrático, tal como está concebido por la Convención Americana, que se respete escrupulosamente el derecho de cada ser humano de expresarse libremente y el de la sociedad en su conjunto de recibir información".

"70. La libertad de expresión es una piedra angular en la existencia misma de una sociedad democrática. Es indispensable para la formación de la opinión pública. Es también conditio sine qua non para que los partidos políticos, los sindicatos, las sociedades cientificas y culturales y, en general, quienes deseen influir sobre la colectividad puedan desarrollarse plenamente. Es, en fin, condición para que la comunidad, a la hora de ejercer sus opciones, esté suficientemente in- 
formada. Por ende, es posible afirmar que una sociedad que no está bien informada no es plenamente libre".

"71. Dentro de este contexto, el periodismo es la manifestación primaria y principal de la libertad de expresión del pensamiento y, por esa razón, no puede concebirse meramente como la prestación de un servicio al público a través de la aplicación de unos conocimientos o capacitación adquiridos en una universidad o por quienes están inscritos en un determinado colegio profesional, como podrá suceder con otras profesiones, pues está vinculado con la libertad de expresión que es inherente a todo ser humano".

"72. El argumento según el cual una ley de colegiación obligatoria de los periodistas no difiere de la legislación similar, aplicable a otras profesiones, no tiene en cuenta el problema fundamental que se plantea a propósito de la compatibilidad entre dicha ley y la Convención. El problema surge del hecho de que el articulo 13, expresamente, protege la libertad de "buscar, recibir y difundir informaciones e ideas de toda indole (...) ya sea oralmente, por escrito o en forma impresa (...)". La profesión de periodista -lo que hacen los periodistas-implica precisamente el buscar, recibir y difundir información. El ejercicio del periodismo, por tanto, requiere que una persona se involucre en actividades que están definidas o encerradas en la libertad de expresión garantizada en la Convención".

"76. La Corte concluye, en consecuencia, que las razones de orden público que son válidas para justificar la colegiación obligatoria de otras profesiones no pueden invocarse en el caso del periodismo, pues conducen a limitar de modo permanente, en perjuicio de los no colegiados, el derecho de hacer uso pleno de las facultades que reconoce a todo ser humano el artículo 13 de la Convención, lo cual infringe principios primarios del orden público democrático sobre el que ella misma se fundamenta".

"79. En consecuencia, la Corte estima que la libertad e independencia de los periodistas es un bien que es preciso proteger y garantizar. Sin embargo, en los términos de la Convención, las restricciones autorizadas para la libertad de expresión deben ser las "necesarias para asegurar" la obtención de ciertos fines legitimos, es decir, que no basta que la restricción sea útil (supra, 46) para la obtención de ese fin, esto es, que se pueda alcanzar a través de ella, sino que debe ser necesaria, es decir, que no pueda alcanzarse razonablemente por otro medio menos restrictivo de un derecho protegido por la Convención. En este sentido, la colegiación obligatoria de los periodistas no se ajusta a lo requerido por el artículo 13.2 de la Convención, porque es perfectamente con- 
cebible establecer un estatuto que proteja la libertad e independencia de todos aquellos que ejerzan el periodismo, sin necesidad de dejar ese ejercicio solamente a un grupo restringido de la comunidad".

"80. También está conforme la Corte con la necesidad de establecer un régimen que asegure la responsabilidad y la ética profesional de los periodistas y que sancione las infracciones a esa ética. Igualmente considera que puede ser apropiado que un Estado delegue, por ley, autoridad para aplicar sanciones por las infracciones a la responsabilidad y ética profesionales. Pero, en lo que se refiere a los periodistas, deben tenerse en cuenta las restricciones del articulo 13.2 y las caracteristicas propias de este ejercicio profesional a que se hizo referencia antes (supra 72-75)".

"81. De las anteriores consideraciones se desprende que no es compatible con la Convención una ley de colegiación de periodistas que impida el ejercicio del periodismo a quienes no sean miembros del Colegio y limite el acceso a éste a los graduados en una determinada carrera universitaria. Una ley semejante contendria restricciones a la libertad de expresión no autorizadas por el artículo 13.2 de la Convención y sería, en consecuencia, violatoria tanto del derecho de toda persona a buscar y difundir información e ideas por cualquier medio de su elección, como del derecho de la colectividad en general a recibir información sin trabas"15.

Ciertamente, la Opinión Consultiva extractada, así como sus votos particulares, dejan a salvo de la norma incorporada por la reforma al No 16 del art. 19 C.P.R. de una eventual contradicción con la Convención Americana sobre Derechos Humanos, ya que la doctrina y jurisprudencia de Corte Interamericana de Derechos Humanos, admite como plenamente compatible con el sistema interamericano de derechos, más aún imperando la libertad de asociación negativa (libertad de colegiación) y libertad de elección de profesiones u oficios, la imposición por ley o por la Constitución de un régimen de responsabilidad ética disciplinaria para los profesionales colegiados o no. En la especie este régimen de responsabilidad ética disciplinaria de profesiones es ope Constitutione y llamada a regir in actum.

\section{Derecho de Reunión}

En el plano de las definiciones el derecho de reunión del artículo 19 № 13 de la Constitución es un derecho fundamental de naturaleza dual: civil y político, distinción fundada en los fines, motivos e intereses de las personas congregadas o reunidas, como

15 Para consultar la doctrina jurisprudencial de la Corte y del sistema interamericano el libro coordinado por García Ramírez (2001), pp. 963-986. 
bien lo señala un jurista clásico como Nicolás Pérez Serrano. Se define el derecho de reunión como "la facultad de toda persona para agruparse voluntaria, tranquila y transitoriamente con otras, en un lugar y con un fin determinado" (M.A. Núñez) ${ }^{16}$.

Por otra parte el texto del artículo 19 No 13 de la Constitución responde a dos fórmulas tradicionales, a saber:

1. La fórmula de la Constitución belga de 1832 que consagra el derecho a reunirse "pacíficamente sin permiso previo y sin armas", lo que refleja la repulsa a reuniones con fines no pacíficos y a la formación de milicias o de grupos paramilitares, que lesionen el monopolio del uso de la fuerza y su dimensión instrumental dada por la posesión o tenencia organizada y profesional de las armas, como ocurre con la fuerza pública y las fuerzas armadas, y que se traduce en la recepción de bienes jurídicos penales en nuestra legislación penal y de control de armas.

2. La fórmula de que las "reuniones públicas" (realizadas en plazas calles y demás lugares de uso público) se someterán a las "disposiciones generales de policía”, reserva reglamentaria que hace excepción a la garantía de reserva de ley, tratándose del desarrollo infraconstitucional de derechos fundamentales.

En cuanto a esta segunda fórmula el Anteproyecto de la Comisión de Estudio de la Nueva Constitución propuso la fórmula del artículo 10 No 4 de la Constitución de 1925 reformada en 1971 (Ley No 17.398, conocida como la reforma constitucional del "estatuto de garantías"), y en cambio el Anteproyecto del Consejo de Estado propuso la fórmula regresiva del texto original de la Constitución de 1925, en orden a someter las "reuniones públicas" a las "disposiciones generales de policía", fundado en que correspondía al Presidente de la República el resguardo del orden público, no pudiendo quedar entregada esta materia a la ley ${ }^{17}$.

Desde el punto de vista dogmático el derecho de reunión nos presenta diversos alcances, que preocupan a autores tradicionales que ligan el derecho de reunión al de la libertad de movilización o bien a libertad de opinión ${ }^{18}$.

En relación a su contenido, podemos situar el derecho de reunión dentro del conjunto de libertades para cuyo ejercicio se requiere la concurrencia de distintas voluntades: nos encontramos ante un derecho individual de ejercicio colectivo. Se trata, a pesar de ser un derecho dual como lo expresamos, de un derecho predominantemente del "ámbito político" como lo son también los de libertad de expresión e información, derecho de asociación, participación política y petición (López González) ${ }^{19}$.

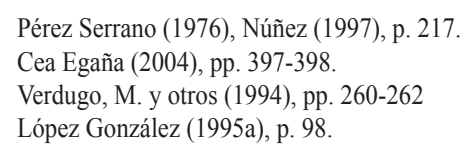


De esta manera, los derechos de "ámbitos políticos" serían un corolario de los de libertad personal. Los primeros completan a los segundos "proyectando el ejercicio de las libertades individuales sobre la libertad colectiva" ${ }^{20}$.

El jurista español FERNÁNDEZ SEGADO entiende que el derecho de reunión ha de ser situado entre los derechos "que se orientan a fortalecer la vertiente social y comunitaria de la persona, tradicionalmente ignorada por la filosofía política enormemente individualista del liberalismo" 21 .

Tal vez esta connotación política ha llevado a la doctrina en épocas pasadas a considerar que el derecho de reunión es un derecho político sin más prescindiendo de otros caracteres que, a nuestro juicio, forman parte de una libertad de naturaleza jurídica compleja o dual como la de reunión.

En este sentido, PRIETO SANCHÍS ha clasificado al derecho de reunión entre los que denomina "derechos de autonomía" entendiendo por tales los que "tienen por finalidad garantizar un ámbito de inmunidad y no sujeción del individuo", por ello, "se configuran como obligaciones negativas o de abstención; o lo que es igual, su satisfacción exige una conducta pasiva y de no interferencia por parte de los sujetos obligados"22. Por lo dicho, es acertado LÓPEZ GONZÁLEZ al sostener: “Tradicionalmente se ha venido entendiendo que la libertad de reunión, al igual que otros derechos y libertades próximos a ella, exigía una mera actitud abstencionista por parte del Estado. Sin embargo, la trascendencia de un derecho como el de reunión, imprescindible en un Estado democrático y que supone una referencia básica indicativa de la situación de las libertades en general, ha llevado progresivamente a su protección positiva por parte de los poderes públicos". Agrega este joven jurista español: "Cabe más bien tratar de delimitar lo que puede ser la reunión a través de una serie de rasgos o elementos que operan a modo de presupuestos necesarios para identificar determinadas situaciones o actos como reuniones. Así, es ya clásica la definición de Claude-Albert Colliard en el sentido de que por reunión habría que entender aquella agrupación de personas organizada o susceptible de serlo, discontinua y momentánea que se produce además con unas finalidades específicas: la defensa de intereses, el intercambio o exposición de ideas o bien la publicidad de problemas"23.

A partir de esta definición dual del derecho de reunión civil y político, aunque predominantemente del "ámbito político", podemos extraer siguiendo a LÓPEZ GONZÁLEZ cuatro elementos o presupuestos básicos que están en el origen del concepto de reunión:

a) El elemento personal. Se trata de una agrupación de personas. Es un derecho de carácter individual, una libertad que corresponde a cada ciudadano pero cuyo ejercicio es necesariamente colectivo. Es un derecho que se ejercita "con otros" en un evidente

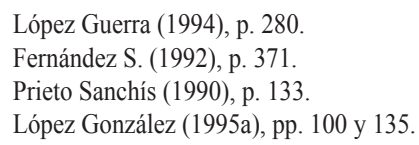


proceso de interacción. Observa López González: "Pero, como ha puesto de relieve el Tribunal Constitucional en su STC 25/1981, de 14 de marzo (F. J.5), los derechos fundamentales son algo que los derechos subjetivos: “(...) son elementos esenciales de un ordenamiento objetivo de la comunidad nacional, en cuanto ésta se configura como marco de una convivencia humana justa y pacífica, plasmada históricamente en el Estado de Derecho y, más tarde, en el Estado social de Derecho o Estado social y democrático de Derecho, según la fórmula de nuestra Constitución”.

b) Elemento finalista. La reunión no constituye un encuentro casual, una mera aglomeración espontanea de personas. A la libertad de reunión le resulta inherente un elemento finalista: la concertación previa entre los reunidos que pretenden lograr con la reunión un objetivo u objetivos concretos relacionados con la defensa de intereses comunes, el intercambio de ideas o incluso la publicidad de problemas.

La concertación hace referencia a la voluntad coincidente de un conjunto de personas que deciden libremente reunirse en un momento y lugar determinados para una finalidad lícita igualmente concreta. Precisamente estas características permiten distinguir las reuniones de otro tipo de actos de mera agregación espontánea. Los sujetos que ejercen el derecho son conscientes de la reunión a la que asisten y de su finalidad. Por ello, está presente en todo momento la nota de la voluntariedad. Precisa los términos: reunión - espectáculos López González al señalar: "Si existirá, por el contrario, una voluntad individual de concurrir al espectáculo, pero en ningún caso concertación tal y como hemos definido ya esta característica. Es decir, los asistentes no se conciertan entre sí para intercambiar ideas, dar publicidad a determinados problemas o defender concretos intereses. Nos parece entonces que pueda suscitar demasiadas dudas la distinta naturaleza de los espectáculos en relación a las reuniones en sentido estricto".

c) El elemento objetivo. El elemento objetivo viene determinado por el lugar específico en el que se celebra la reunión. En relación al elemento objetivo, Fernández Segado ha considerado que "atiende al lugar de celebración de la reunión, que ha de ser público, pues las reuniones que no se celebren en tales lugares (sean recintos cerrados o lugares de tránsito público) no serán objeto del derecho de reunión”.

Tras esta afirmación late la relación entre libertad de reunión e inviolabilidad del domicilio. De esta forma si no nos encontramos ante una reunión en lugar público, es decir, si la reunión se lleva a cabo en un domicilio particular, por ejemplo, no estaremos en presencia de la libertad de reunión sino ante una manifestación del derecho a la intimidad personal o privacidad.

d) El elemento temporal. La reunión se caracteriza por la nota de la transitoriedad. En efecto, a diferencia de la asociación que se distingue por la existencia de un vínculo permanente en el tiempo entre los asociados, la reunión tiene una duración específica, determinada. Agrega López González: "La conclusión de la reunión supone la ruptura del vínculo que unía a los reunidos. Una nueva reunión, incluso de las mismas personas, supondrá el nacimiento de un nuevo vínculo temporal. En consecuencia, 
incluso en las reuniones celebradas por los miembros de una asociación deberemos distinguir entre el hecho asociativo que incorpora un elemento espiritual de unión entre los partícipes con independencia de que estén o no reunidos, y la reunión misma que mantiene su independencia como libertad al servicio de la asociación, conservando así su transitoriedad característica”.

Sólo resta destacar que el derecho de reunión tiene en esta dimensión colectiva, que lo conecta fuertemente con el ámbito político, no deja de ser un derecho también civil, que en ocasiones pude mirar sólo al interés privados de los congregados o reunidos. Es acertado entonces NOGUEIRA ALCALÁ al sostener: "Este es un derecho individual con una clara proyección social y de ejercicio colectivo que requiere de la colaboración y apoyo de otras personas para poder concretarse, ya que solo puede ejercerse en conjunto con otros individuos, siendo un instrumento a través del cual los diversos grupos sociales pueden expresar y demandar sus fines e intereses. En tal sentido, este derecho tiene un aguzado perfil y vertiente política." Agrega este autor la conexión del derecho de reunión con otros derechos fundamentales: "Para parte de la doctrina comparada, se considera al derecho de reunión como una manifestación colectiva de la libertad de expresión, en la medida que posibilita la libre discusión de ideas y su publicidad, mientras en la doctrina norteamericana se le considera un desdoblamiento del derecho de petición, en la medida que, para ejercer este último, se entiende como esencial a la idea de gobierno republicano o de que las personas puedan reunirse pacíficamente para tratar asuntos públicos" ${ }^{24}$.

El corolario de lo expresado en esta dimensión dual del derecho de reunión, aunque con predominio de lo político, que nos lleva a estudiarlo como un derecho político más, la estrecha conexión con el sistema democrático pluralista. En palabras de NOGUEIRA ALCALÁ: "Puede sostenerse que el derecho de reunión es un derecho instrumental del principio democrático participativo, en la medida en que es el vehículo que posibilita canalizar la libertad de opinión, la libertad religiosa, formular peticiones, hacer presente demandas e intereses de determinados sectores sociales o políticos, como asimismo solicitar reparación de daños o lesiones causadas. El derecho de reunión no es solo un derecho de autonomía que se contenta con la abstención estatal, este derecho fundamental requiere de un rol activo del Estado que no se contenta con no interferir en el ejercicio del mismo, sino que requiere que adopte medidas positivas destinadas a garantizar efectivamente la práctica y ejercicio efectivo del derecho, incluso en la relación entre individuos, para impedir que unos obstaculicen o impidan mediante contramanifestaciones el desarrollo del derecho de otros miembros de la sociedad a reunirse o manifestarse, aunque estos últimos sean minoritarios. En tal sentido, recae en la autoridad gubernativa asegurar, mediante la protección de las fuerzas de orden y seguridad públicas, el ejercicio del derecho fundamental de reunión dentro del marco del Estado constitucional democrático”25.

Nogueira Alcalá (2008), p. 524
Nogueira Alcalá (2008), p. 524. 
Por todo ello con LÓPEZ GONZÁLEZ es menester distinguir entre reuniones y espectáculos públicos o meras aglomeraciones de personas, como antes se ha explicado. En nuestro país la legislación ha reconocido los espectáculos públicos como distintos al derecho de reunión, como ocurre con la Ley No 19.327 que regula concentraciones en los estadios con ocasión de los espectáculos de fútbol profesional. Asimismo, tales espectáculos públicos pueden realizarse en lugares abiertos al público, pero privados y no en rigor en lugares de "uso público". En el mismo sentido insiste NOGUEIRA ALCALÁ: "En efecto, la reunión a diferencia del simple encuentro o de una aglomeración de personas requiere de un mínimo de organización y convocación con fines precisos y determinados, de los cuales carecen el encuentro casual o la aglomeración. A su vez, el hecho de concretarse la reunión por un lapso limitado y breve, que puede durar algunos minutos u horas, vale decir, tiene un carácter momentáneo, lo que la diferencia de una asociación, la que tiene las mismas características de una reunión pero se diferencia por juntarse organizadamente en forma permanente y no momentáneamente, permaneciendo los objetivos del grupo aunque desaparezca el contacto físico de las personas a diferencia de lo que ocurre en la reunión, como lo analizaremos cuando tratemos el derecho de asociación”26.

Un tratamiento distinto exige la reunión en lugares privados, como son el domicilio, la oficina profesional, entre otros lugares, está fuertemente interrelacionada con los derechos a la inviolabilidad del hogar y la protección de la vida privada de las personas, la que evidencia la importancia del carácter dual de este derecho ya que es en este campo donde se despliega su dimensión civil, y en donde no cabe reserva reglamentaria, sino una estricta reserva de ley. Lamentablemente Constitución, como ocurre en forma generalizada en el derecho constitucional comparado democrático, tiende a regular fundamentalmente el derecho de reunión en lugares de uso público y la somete a reserva reglamentaria.

Por ello coincido con la crítica de Constitutione ferenda que realiza Nogueira Alcalá a la reserva reglamentaria del derecho de reunión en lugares públicos y su contradicción con estándares garantistas del derecho internacional de los derechos humanos. Señala NOGUEIRA ALCALÁ: "El derecho de reunión como todos los demás derechos fundamentales están garantizados normativamente por el principio de reserva legal exigido para la regulación y restricción del ejercicio de derechos como lo exigen las convenciones internacionales de derechos humanos, específicamente la Convención Americana de Derechos Humanos, en su artículo 15º, constituyendo una vulneración evidente de dichas obligaciones internacionales, el entender el texto constitucional que dispone que el ejercicio del derecho de reunión en lugares públicos se regirá "por las disposiciones generales de policía", en el sentido de que el derecho fundamental analizado pueda estar sometido a las regulaciones administrativas de autoridades gubernativas (Ministerio del Interior, intendentes y gobernadores) como establece alguna jurisprudencia de tribunales ordinarios o alguna parte de la

26 Nogueira Alcalá (2008), p. 525. 
doctrina al interpretar el inciso $2^{\circ}$ del artículo 19 No 13 de la Carta Fundamental. Dicha interpretación vulnera tanto el derecho de reunión mismo contenido en el artículo 15 de la Convención Americana antes transcrito, como los artículos $1^{\circ}$ y $2^{\circ}$ de la misma, los cuales exigen a los estados partes, asegurar y garantizar los derechos en los términos establecidos por la Convención, derechos que son de ejecución directa e inmediata, como asimismo, si no estuvieren asegurados al momento de ratificar dicho tratado, el Estado parte debe adecuar su ordenamiento jurídico a las obligaciones convencionales, ordenamiento que parte desde la Constitución misma, como ya lo determinó la Corte Interamericana de Derecho Humanos en el caso "La última tentación de Cristo" ${ }^{27}$.

Finalmente, la regulación infraconstitucional del derecho de reunión que precisa sus contornos de licitud, debe ser en la imposición de límites congruente con el sistema democrático pluralista en funcionamiento. Asimismo, las regulaciones y restricciones al ejercicio del derecho de reunión, deben cumplir el requisito exigido por la Convención Americana sobre Derechos Humanos de "que sean necesarias en una sociedad democrática, en interés de la seguridad nacional, de la seguridad o del orden públicos, o para proteger la salud o la moral públicas o los derechos y libertades de los demás”.Por otra parte subraya NOGUEIRA ALCALÁ: “... las regulaciones legales nunca pueden establecer como requisito para ejercer el derecho el de obtener un permiso previo de la autoridad gubernativa, ya que ello afecta el contenido esencial del derecho de reunión tal como lo establece la Carta Fundamental"28.

En este mismo orden de ideas es menester precisar que en nuestro país las "disposiciones generales de policía” (D.S. No 1.086 de M. del Interior, de 1983) establecen como mecanismo de control de orden y seguridad pública de las reuniones públicas el "aviso previo" a la autoridad de gobierno interior, la que podrá prohibir, fundada y razonablemente la reunión. Precisando el alcance de la preadvertencia y los límites de esta atribución de gobierno interior, NÚÑEZ señala muy atinadamente: "No está demás traer aquí a colación un principio de derecho público que sirve para proteger a todas las libertades fundamentales, nos referimos al principio o prohibición de la arbitrariedad. La aplicación de este principio ya ha quedado insinuada al referirnos a la razonabilidad o sensatez de la exigencia del aviso previo y que se manifiesta en la incompetencia de la autoridad para exigir avisos cada vez que no concurre la ratio que justifica la obligación de preadvertirla. Esta última no es otra cosa que la posibilidad de un desorden público con ocasión de la reunión. Por otra parte, resulta también necesario recordar que las facultades de la autoridad se encuentran sometidas a importantes limitaciones: ella debe tener la obligación de responder fundadamente dentro de un lapso razonable y no debe encontrarse habilitada para prohibir a priori las reuniones en los lugares abiertos al público. Sólo de esta manera se garantiza el adecuado respeto por la libertad de reunión. Excepcionalmente

Nogueira Alcalá (2008), pp. 529-530.

Nogueira Alcalá (2008), p. 531. Núñez (1997), pp. 220-221. 
el régimen de preadvertencia a la autoridad administrativa puede extenderse a las reuniones masivas en lugares privados pero abiertos al público. Este puede ser el caso de las concentraciones que se producen con ocasión de espectáculos deportivos o artísticos, situaciones en que no sólo resulta necesario resguardar el orden público (especialmente cuando finaliza el espectáculo) sino también la seguridad e integridad de los participantes".

\section{Conclusiones: algunos problemas dogmáticos y jurisprudenciales}

A título de conclusiones del abordaje propedéutico de los derechos de asociación y de reunión nos parece útil retomar la definición dual, ya que con plasticidad sitúa a estos derechos en los planos individual y colectivo en que se desenvuelven, los fines e intereses privados y públicos concernidos, y la mayor o menor organización que importan en cuanto agregaciones voluntarias de personas, en prosecución de fines individuales o colectivos.

Por otra parte, en la perspectiva Constitutione ferenda parece superada en gran parte la vieja cuestión de la colegiación obligatoria y de la tuición ética de las profesiones, quedando estos temas entregados hoy más bien al desarrollo legislativo del derecho de asociación. Subsiste en relación al derecho de reunión, primero sustantivamente diferenciar entre la reunión y el espectáculo público, y segundo, la necesidad de introducir para el desarrollo infraconstitucional del derecho de reunión la garantía normativa de reserva de ley, de suerte que la regulación, y límites que se introduzcan al ejercicio del derecho en lugares de uso público, y en lugares de acceso público o en lugares privados, para la conservación del orden público y la seguridad pública, o los derechos de terceros, quede subordinado a la decisión de la "ley parlamentaria", a la representación política y en último término al consenso que dichas formas imponen.

También en esta perspectiva de Constitutione ferenda es necesario proyectar el derecho de reunión explícitamente al derecho de manifestación pública, todo con expresa reserva legal, para que desde las coordenadas del pluralismo social, ideológico y político no se criminalice de iure o de facto, a través de leyes penales especiales o protocolos de seguridad pública y de orden público dirigido a la fuerza pública, la protesta social. Se suma así el derecho de reunión y el derecho de manifestación pública a la necesaria depuración del derecho constitucional positivo de los vestigios autoritarios del constituyente de 1980 que se traducen en un verdadero "derecho constitucional del enemigo". 


\section{Referencias bibliográficas}

ALDUNATE LIZANA, Eduardo (2008): Derechos Fundamentales. Santiago, Legal Publishings.

ARGANDONAA, Manuel (1980): "Algunas Consideraciones sobre los Colegios Profesionales". Revista de Derecho Público, No 27, U. de Chile.

BULNES ALDUNATE, Luz (1981): "La libertad del trabajo y su Protección en la Constitución de 1980". En XI Jornadas Chilenas de Derecho Público, Facultad de Derecho, U. de Chile, en Revista de Derecho Público No 29-30.

CEA EGAÑA, José Luis (2004): Derecho Constitucional Chileno. Derechos, Deberes y Garantías. T. II. Santiago, Ed. Universidad Católica.

COVIELLO, Nicolás (1938): Doctrina General del Derecho Civil (trad. De F. De J. Tena de la 4a edición italiana) México DF, Unión Tipográfica Editorial Hispano Americana.

FERNÁNDEZ S., Francisco (1992): El sistema constitucional. Madrid, Dikinson.

FERRARA, Francisco (1929): Teoría de las Personas Jurídicas (trad. E. Ovejero y Maury) Madrid, Edit. Reus, 1929.

GARCÍA RAMÍREZ, Sergio (2001): "La jurisprudencia de la Corte Interamericana de Derechos Humanos", México, UNAM-CIDD.HH.

GARRIGOU LAGRANCE, J. M. (1974): Asociaciones y poderes públicos. Madrid, Edit. IEP.

LÓPEZ GONZÁLEZ, José Luis (1995a): El derecho de reunión y manifestación en el ordenamiento constitucional español. Madrid, Edic. Ministerio de Justicia e Interior.

LÓPEZ GONZÁLEZ, José Luis (2001b): Los Colegios Profesionales como Corporaciones de Derecho Público: un estudio en clave constitucional. Valencia, Edit. Nomos.

LÓPEZ GUERRA, Luis y otros (1994): Derecho Constitucional. 2 vol. y 1 suplemento. T. I. Valencia, Edit. Tirant le Blanch.

LUCAS MURILLO DE LA CUEVA, E. (1996): El derecho de Asociación. Madrid, 1996.

MUÑOZ B., Ana María (1999): "Las Jurisdicciones Domésticas a través de las Sentencias de Protección”, en XXX Jornadas Chilenas de Derecho Público, F. de Derecho, U. de Valparaíso, 2 vol., Tomo II.

NOGUEIRA ALCALÁ, Humberto (2008): Derechos Fundamentales y Garantías Constitucionales. T. II. Santiago, CECOCH-Librotecnia, 2008.

NÚNEEZ, Manuel Antonio (1997): "Las libertades de reunión y asociación”, recogidas en libro colectivo de VV. AA.: Lecciones de Derechos Humanos, Edeval, Valparaíso, 1997. 
PÉREZ ROYO, Javier (1999): Curso de Derecho Constitucional. $6^{\circ}$ Ed. MadridBarcelona, Edit. M Pons.

PÉREZ SERRANO, Nicolás (1976): Tratado de Derecho Político. Madrid, Edit. Civitas.

PRIETO SANCHÍS, Luis (1990): Estudio sobre derechos fundamentales. Madrid, Edit. Debate.

RÍOS ÁLVAREZ, Lautaro (1996): “Los Colegios Profesionales”, en Revista de Derecho Público No 59, U. de Chile.

RÍOS ÁLVAREZ, Lautaro (1999): "Las Asociaciones, el Derecho de Asociación y los Colegios Profesionales", en XXX Jornadas Chilenas de Derecho Público, F. de Derecho, U. de Valparaíso, 2 vol., Tomo I.

SCHMITT, Carl (1982): Teoría de la Constitución (trad. F. Ayala y epílogo de M. García Pelayo) Madrid, Alianza Edit.

SILVA BASCUÑÁN, Alejandro (2009): "Derecho de reunión” recogido en el libro: Temas actuales de derecho constitucional. Homenaje al profesor Mario Verdugo Marinkovic, Edic. de la Asociación Chilena de Derecho Constitucional - Editorial Jurídica de Chile, Santiago, 2009, pp. 305-317.

SILVA BASCUÑÁN, Alejandro (1989): "Los Colegios Profesionales en la Constitución”. XVI Revista Chilena de Derecho, № 2, PUC.

STEIN, EKKEHART (1973): Derecho Político (trad. F. Sainz M. y estudio de F. Rubio Llorente). Madrid, Edit. Aguilar.

TOLIVAR ALAS, Leopoldo (1991): "La configuración constitucional del derecho a la libre elección de profesión u oficio”, en libro coordinado por S. Martín Retortillo. Estudios sobre la Constitución Española. Homenaje al profesor Eduardo García de Enterría. 5 vol., tomo II "De los Derechos y Deberes Fundamentales". Madrid, Edit. Civitas.

VERDUGO, M. y otros (1994): Derecho Constitucional. 2 vol., T.I. Santiago, Editorial Jurídica de Chile.

VILLAR PALASÍ, José Luis y VILLAR EZCURRA, José Luis (1991): "La libertad constitucional del ejercicio profesional”, en: Estudios sobre la Constitución Espanóla. Homenaje al profesor Eduardo García de Enterría. 5 vol., tomo II "De los Derechos y Deberes Fundamentales". Madrid, Edit. Civitas. 